\title{
Changing mortality patterns in East and West Germany and Poland. II: Short-term trends during transition and in the 1990s
}

\author{
Ellen Nolte, Vladimir Shkolnikov, Martin McKee
}

\begin{abstract}
Objectives-To examine trends in life expectancy at birth and age and cause specific patterns of mortality in the former German Democratic Republic (GDR) and Poland during political transition and throughout the 1990s in both parts of Germany and in Poland.

Methods-Decomposition of life expectancy by age and cause of death. Changes in life expectancy during transition by cause of death were examined using data for $1988 / 89$ and $1990 / 91$ for the former GDR and Poland; examination of life expectancy changes after transition were based on 1992-97 data for Germany and 1991-96 data for Poland.

Results-In both the former GDR and Poland male life expectancy at birth declined by almost one year during transition, mainly attributable to rising death rates from external causes and circulatory diseases. Female life expectancy in Poland deteriorated by 0.3 years, largely attributable to increasing circulatory mortality among the old, while in East German female rising death rates in children and young adults were nearly outbalanced by declining circulatory mortality among those over 70. Between 1991/92 and 1996/ 97, male life expectancy at birth increased by 2.4 years in the former GDR, 1.2 years in old Federal Republic, and 2.0 years in Poland (women: 2.3, 0.9, and 1.2 years). In East Germany and Poland, the overall improvement was largely attributable to falling mortality among men aged 40-64,
\end{abstract}

European Centre on Health of Societies in Transition, London School of Hygiene and Tropical Medicine, Keppel Street, London WC1E 7HT

E Nolte

M McKee

Centre of Demography and Human Ecology, Institute for Economic Forecasting, Moscow, Russian Federation V Shkolnikov

Correspondence to: Ellen Nolte

(ellen.nolte@1shtm.ac.uk)

Accepted for publication 3 April 2000

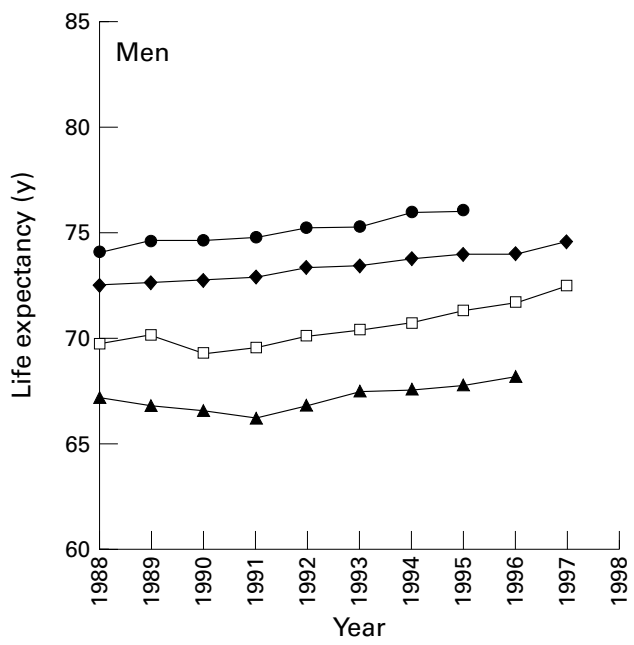

while those over 65 contributed the largest proportion to life expectancy gains in women. The change in deaths among men aged 15-39 accounted for 0.4 of a year to life expectancy at birth in East Germany and Poland, attributable largely to greater decreases from external causes. Among those over 40, absolute contributions to changing life expectancy were greater in the former GDR than in the other two entities in both sexes, largely attributable to circulatory diseases. A persisting Eastwest life expectancy gap in Germany of 2.1 years in men in 1997 was largely attributable to external causes, diseases of the digestive system and circulatory diseases. Higher death rates from circulatory diseases among the elderly largely explain the female life expectancy gap of approximately one year.

Conclusions-This study provides further insights into the health effects of political transition. Post-transition improvements in life expectancy and mortality have been much steeper in East Germany compared with Poland. Changes in dietary pattern and, in Germany, medical care may have been important factors in shaping posttransition mortality trends.

(F Epidemiol Community Health 2000;54:899-906)

The transition in central and eastern Europe in the late 1980s offers valuable opportunities to study the impact of major political and economic change on health. Much of the research published is, however, from a few

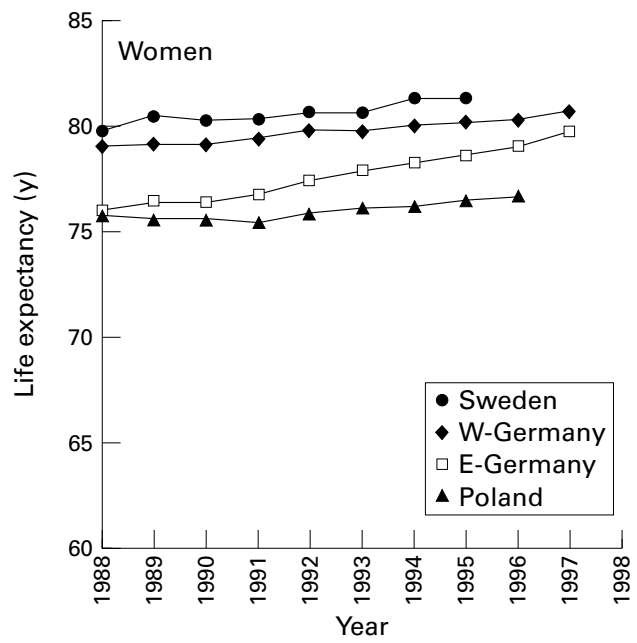

Figure 1 Life expectancy at birth in East and West Germany, Sweden and Poland in the 1990s. 
countries, especially Poland and the Czech Republic. ${ }^{12}$ Less work has been undertaken in the former German Democratic Republic (GDR).

We have described how the health experience of the former GDR differed from neighbours since transition. ${ }^{3}$ While some experienced improvements in life expectancy in the 1990 s, the rate of increase was much greater in the former GDR. This improvement was also substantially greater than that in West Germany, although from a lower baseline. A gap in life expectancy at birth between the two parts of Germany, however, remained, at two years for men and one year for women in 1997.

In this paper, the second of two linked studies, we explore some immediate causes of the performance of the former GDR since unification and the causes of the continuing gap between the two parts of Germany.

\section{Methods}

This paper builds on one examining long term trends in the two parts of Germany and Poland since the 1960s. ${ }^{3}$ We examine trends in life expectancy at birth and age and cause specific patterns of mortality in the former GDR and Poland during transition and throughout the 1990s. The analyses decompose life expectancy by age and cause of death. Data and methods have been described in detail in the first study. ${ }^{3}$

To examine mortality during the transition in the former GDR and Poland, changes in life expectancy were decomposed by age and cause of death using 1989-1990 data for East Germany and 1988-1991 data for Poland. To enable comparisons in the years after transition, a six year period was chosen for each entity. Changing coding procedures in the former GDR in October $1990^{4}$ may have implications for comparability of data in 1990 and 1991 so the year 1992 was taken as baseline for the two parts of Germany, with analyses extending to 1997. Mortality data for Poland were only available to 1996 so there the period of analysis was 1991-96.

\section{Results}

Changes in life expectancy at birth in both parts of Germany and, for comparison, Sweden, with the highest life expectancy in western Europe, and Poland are shown in figure 1. While all countries have experienced improvements in the 1990s, the former GDR has done better than the others but a short lived deterioration immediately after the transition in Poland was also observed in East Germany between 1989 and 1990. By 1997, East Germany had somewhat caught up with the

Table 1 Contribution, in years, of major causes of death and deaths at different age groups to the overall change in life expectancy

\begin{tabular}{|c|c|c|c|c|c|c|c|c|}
\hline & Infectious & Neoplasms & Circulatory & Respiratory & Digestive & Other diseases & External & All \\
\hline \multirow{2}{*}{\multicolumn{9}{|c|}{ East Germany: 1992-1997 }} \\
\hline & & & & & & & & \\
\hline 0 & 0.0028 & 0 & 0.007 & 0.0181 & -0.0042 & 0.0545 & 0.0209 & 0.099 \\
\hline $1-14$ & -0.0054 & 0.0126 & 0.0014 & 0.002 & 0.0042 & 0.0107 & 0.0064 & 0.0318 \\
\hline $15-39$ & 0.0015 & 0.016 & 0.0467 & 0.0062 & 0.0493 & 0.0679 & 0.2144 & 0.4018 \\
\hline $40-64$ & 0.0031 & 0.1558 & 0.4344 & 0.0713 & 0.1361 & 0.0965 & 0.1305 & 1.0276 \\
\hline $65+$ & 0.0065 & 0.0067 & 0.6048 & 0.1088 & 0.0197 & 0.0038 & 0.0508 & 0.8009 \\
\hline Total & 0.0085 & 0.1911 & 1.0943 & 0.2064 & 0.2051 & 0.2334 & 0.423 & 2.3611 \\
\hline \multicolumn{9}{|l|}{ Female } \\
\hline 0 & -0.0016 & -0.0065 & 0.0032 & 0.0065 & -0.0032 & 0.1153 & 0.0243 & 0.138 \\
\hline $1-14$ & -0.006 & 0.0065 & -0.0003 & 0.004 & 0.0022 & 0.0182 & 0.0394 & 0.0638 \\
\hline $15-39$ & -0.0016 & 0.0497 & 0.0259 & 0.0051 & 0.0131 & 0.0234 & 0.0503 & 0.1659 \\
\hline $40-64$ & 0.0018 & 0.1316 & 0.2463 & 0.0294 & 0.0806 & 0.0837 & 0.0637 & 0.6371 \\
\hline $65+$ & -0.0001 & 0.0855 & 0.9339 & 0.0862 & 0.0408 & 0.0432 & 0.1185 & 1.3079 \\
\hline Total & -0.0075 & 0.2668 & 1.209 & 0.1312 & 0.1335 & 0.2838 & 0.2962 & 2.3127 \\
\hline \multicolumn{9}{|c|}{$\begin{array}{l}\text { West Germany: 1992-97 } \\
\text { Male }\end{array}$} \\
\hline 0 & 0.0025 & -0.0011 & 0.0007 & 0.0048 & -0.0002 & 0.0859 & 0.0002 & 0.0928 \\
\hline $1-14$ & 0.0016 & 0.0082 & -0.0025 & 0.0012 & 0.001 & 0.0083 & 0.0267 & 0.0443 \\
\hline $15-39$ & 0.0387 & 0.023 & 0.0095 & 0.0028 & 0.0133 & 0.0329 & 0.0685 & 0.1889 \\
\hline $40-64$ & 0.0199 & 0.1475 & 0.1839 & 0.0199 & 0.0236 & -0.0377 & 0.031 & 0.3884 \\
\hline $65+$ & -0.0098 & 0.1146 & 0.3306 & 0.0404 & 0.0174 & -0.0374 & 0.0253 & 0.481 \\
\hline Total & 0.0529 & 0.2922 & 0.5222 & 0.0691 & 0.0551 & 0.052 & 0.1517 & 1.1954 \\
\hline \multicolumn{9}{|l|}{ Female } \\
\hline 0 & 0.002 & 0.0013 & 0.001 & 0.0029 & -0.0003 & 0.065 & 0.0014 & 0.0733 \\
\hline $1-14$ & -0.0018 & 0.0036 & 0.0016 & 0.0026 & 0.0004 & 0.0086 & 0.019 & 0.034 \\
\hline $15-39$ & 0.0051 & 0.0185 & 0.0071 & 0.0025 & 0.0117 & 0.0109 & 0.0329 & 0.0887 \\
\hline $40-64$ & -0.0058 & 0.0788 & 0.047 & 0.0016 & 0.0101 & -0.0005 & 0.0184 & 0.1492 \\
\hline $65+$ & -0.0132 & 0.1157 & 0.4029 & -0.0161 & 0.0098 & -0.0184 & 0.0463 & 0.5271 \\
\hline Total & -0.0137 & 0.2179 & 0.4596 & -0.0065 & 0.0317 & 0.0656 & 0.118 & 0.8723 \\
\hline \multirow{2}{*}{\multicolumn{9}{|c|}{$\begin{array}{l}\text { Poland: } 1991-96 \\
\text { Male }\end{array}$}} \\
\hline & & & & & & & & \\
\hline 0 & 0.0215 & -0.0011 & 0.0048 & 0.0214 & 0.0057 & 0.1585 & 0.0113 & 0.2258 \\
\hline $1-14$ & 0.0079 & 0.0029 & -0.0004 & 0.0052 & 0.0038 & 0.0028 & 0.0454 & 0.0681 \\
\hline $15-39$ & -0.0048 & 0.019 & 0.1057 & 0.0052 & -0.0145 & 0.0278 & 0.3021 & 0.4402 \\
\hline $40-64$ & 0.0179 & 0.0781 & 0.56 & 0.0494 & -0.0154 & 0.0467 & 0.0969 & 0.8335 \\
\hline $65+$ & 0.0102 & -0.0746 & 0.3967 & 0.0313 & 0.0135 & 0.0261 & 0.0224 & 0.4259 \\
\hline Total & 0.0527 & 0.0243 & 1.0668 & 0.1125 & -0.0069 & 0.2619 & 0.4781 & 1.9935 \\
\hline \multicolumn{9}{|l|}{ Female } \\
\hline 0 & 0.019 & 0.0018 & 0.0081 & 0.0236 & 0.0017 & 0.096 & 0.0031 & 0.1555 \\
\hline $1-14$ & 0.0043 & 0.0061 & 0.001 & -0.0032 & -0.0017 & 0.0217 & 0.0254 & 0.0537 \\
\hline $15-39$ & 0.0012 & 0.0206 & 0.0317 & 0.0067 & -0.0031 & 0.0297 & 0.0612 & 0.148 \\
\hline $40-64$ & 0.0038 & 0.0246 & 0.2392 & 0.0153 & 0.0188 & 0.0648 & 0.0286 & 0.3949 \\
\hline $65+$ & 0.0032 & -0.0556 & 0.4673 & -0.0088 & 0.0069 & 0.0449 & 0.0185 & 0.4766 \\
\hline Total & 0.0315 & -0.0025 & 0.7473 & 0.0336 & 0.0226 & 0.2571 & 0.1368 & 1.2287 \\
\hline
\end{tabular}



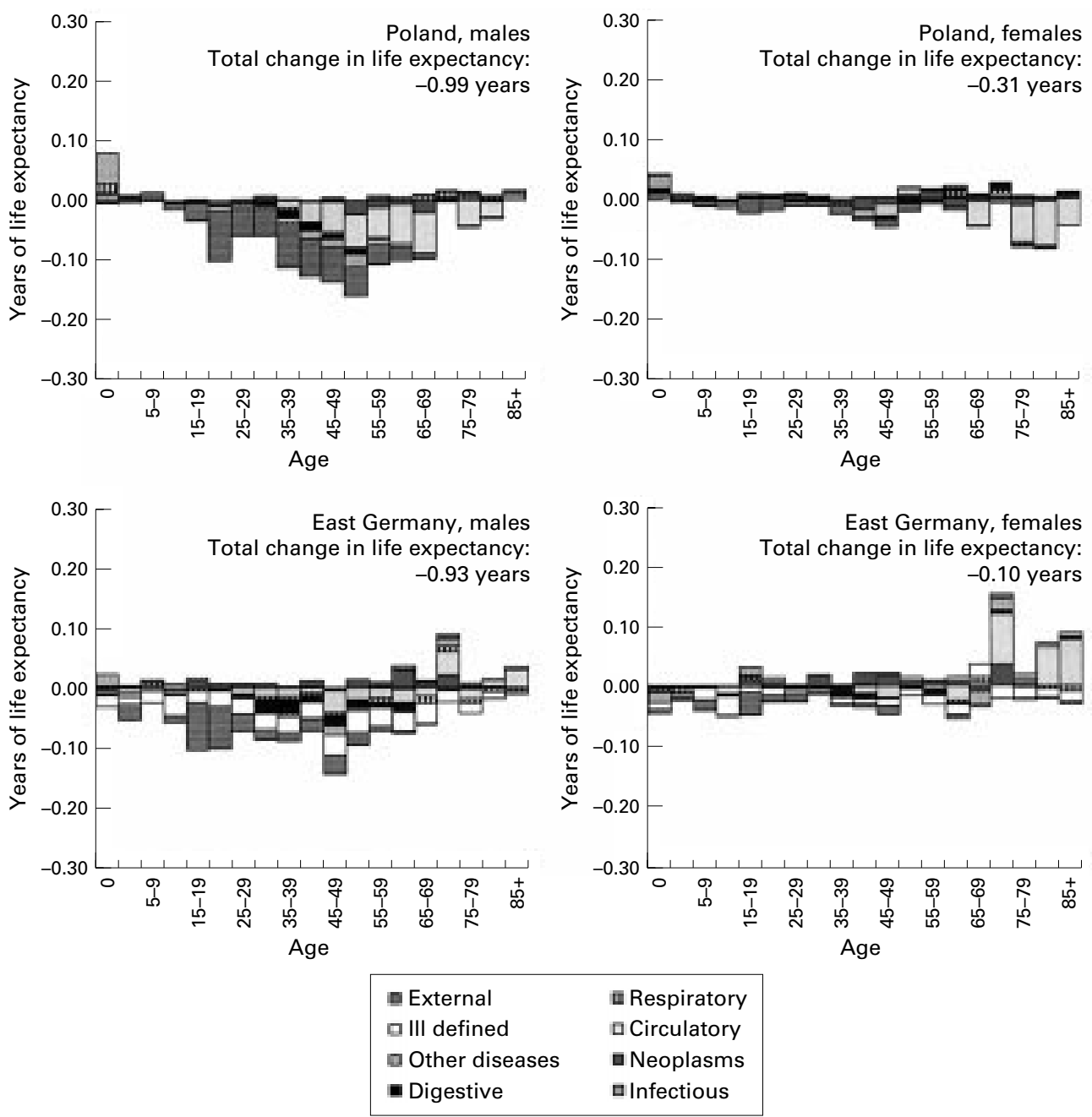

Figure 2 Contribution of age and cause of death to overall changes in life expectancy at birth between 1988/89 and 1990/91: East Germany and Poland.

west, with life expectancy at birth reaching 72.4 compared with 74.5 years in the west for men and 79.7 and 80.6 respectively in women. Poland continued to lag behind, at 68.1 in men and 76.6 in women.

Figure 2 examines the contribution of deaths at different ages and from different causes to changes in life expectancy in the former GDR and Poland between 1988/89 and 1990/91. The sum of values, negative and positive, represents the change in life expectancy at birth in years, amounting to a loss of approximately one year in men in both, the former GDR and Poland, while in women the corresponding figures were -0.1 and -0.3 years, respectively.

In both countries, deaths among men at all ages rose but were somewhat counterbalanced by improvements in infant mortality in Poland and deaths at over 70 in the former GDR. In Poland, the worsening situation for adult men was mostly attributable to external causes with circulatory diseases contributing increasingly in the middle aged. The former GDR exhibits a complex picture as the deterioration in male mortality has included rising death rates from ill defined conditions, making a precise analysis difficult. However, rising death rates from external causes have contributed considerably to male mortality, particularly at younger ages and in children under 5 , while in older ages digestive and circulatory diseases were also important.

The worsening in female life expectancy in Poland was largely attributable to circulatory diseases among the elderly and, among those under 60 , to external causes, although counterbalanced by improvements in infant mortality. In contrast, in the GDR, the larger rise in deaths, particularly in infants, children and young adults, was almost compensated by improvements among those over 70, largely attributable to circulatory diseases.

Figure 3 examines the components of the changes in life expectancy between 1991/92 and 1996/97 in both parts of Germany and in Poland. The overall improvements were, for males, 2.4 years in the former GDR, 1.2 years in the old FRG, and 2.0 years in Poland. For women the corresponding figures were 2.3 years, 0.9 years, and 1.2 years.

In all countries, fewer deaths at all age groups contributed to gains in life expectancy over time except males aged 1-4 years in East Germany. Among East German men, $43 \%$ of the overall improvement was attributable to falling mortality among those aged 40-64 (table 1). A further $33 \%$ was attributable to falling deaths among those aged 65 or over. 

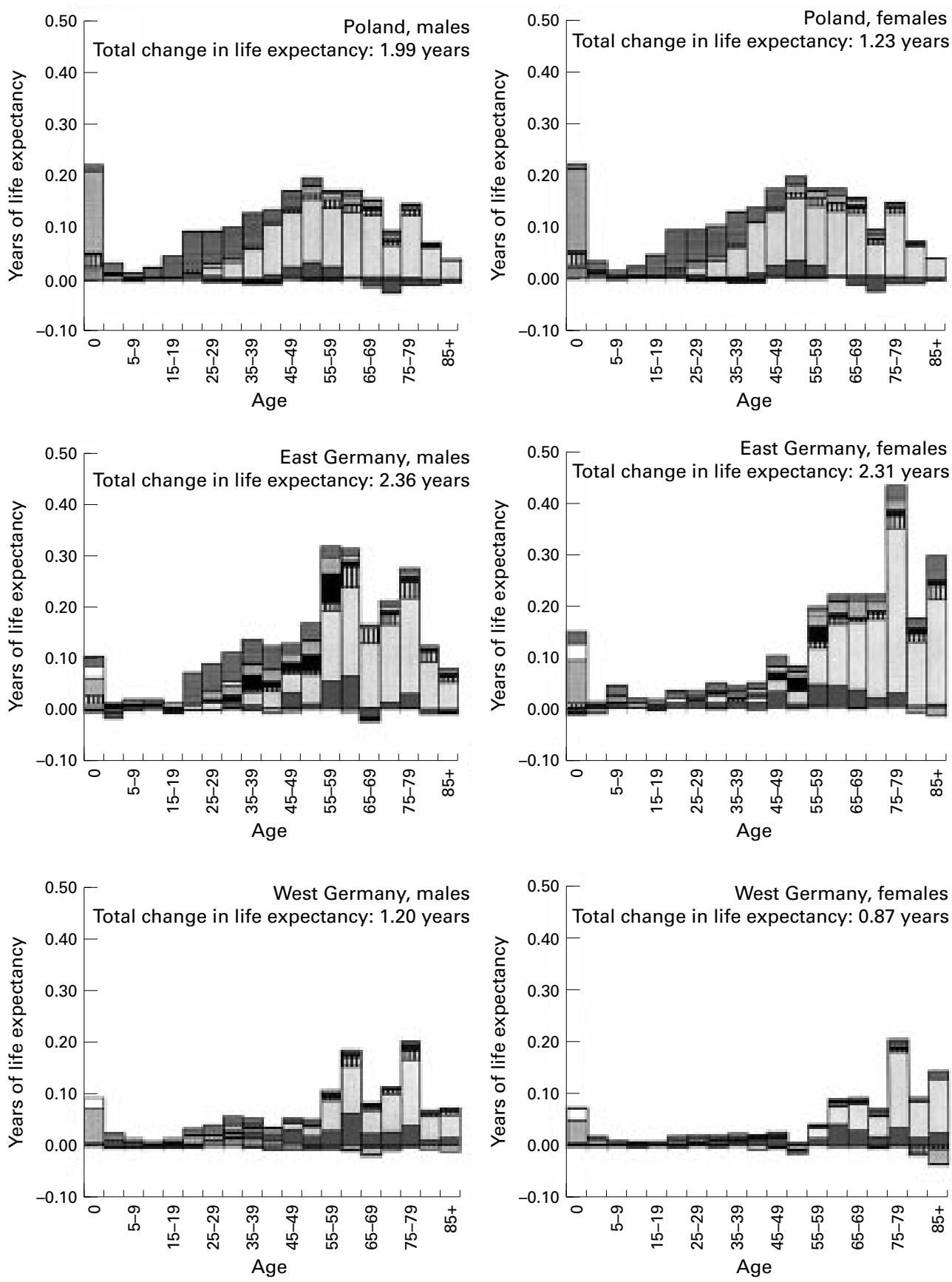

\begin{tabular}{|ll|}
\hline External & a Respiratory \\
a III defined & a Circulatory \\
a Other diseases & a Neoplasms \\
- Digestive & a Infectious \\
\hline
\end{tabular}

Figure 3 Contribution of age and cause of death to overall changes in life expectancy at birth between 1991/92 and 1996/97: East and West Germany and Poland.

Among women, while the overall improvement in life expectancy was similar, over half of the fall was caused by lower deaths among the over 65s (fig 3). This was not seen in Poland. Declining deaths from circulatory diseases and external causes accounted for almost two thirds of the overall improvement. Falling infant mortality contributed little in Germany, at $4-6 \%$ in the East and $8 \%$ in the west, but was slightly more important in Poland, at about $12 \%$.
Changes in deaths among men aged 15-39 accounted for 0.4 of a year in east Germany, double that in West Germany but similar to that in Poland (table 1). The relative contribution by this age group was similar in both parts of Germany, at about $16 \%$, while slightly more important in Poland, at $22 \%$. Among women, the relative contribution of deaths in this age group was lowest in East Germany, at $7 \%$, and highest in Poland, at $12 \%$. 

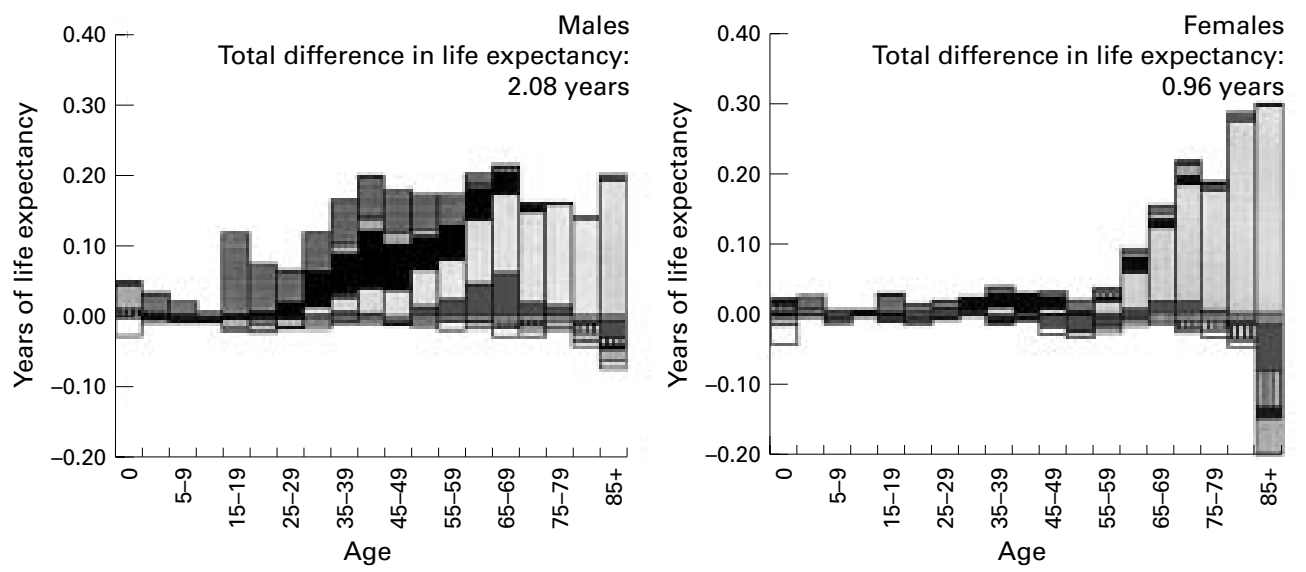

\begin{tabular}{|ll|}
\hline External & a Respiratory \\
$\square$ III defined & aCirculatory \\
a Other diseases & a Neoplasms \\
a Digestive & a Infectious
\end{tabular}

Figure 4 Contribution of age and cause of death to overall differences in life expectancy at birth between the two parts of Germany in 1997.

Among those aged over 40 , contributions to changing life expectancy were greater in the former GDR than in the other two entities. In absolute terms, this was attributable, largely, to declining deaths from circulatory disease although, compared with the old FRG, external causes among men also contributed. In relative terms, declining mortality from circulatory diseases in this age group was equally important in both parts of Germany, contributing about $60 \%$ to the overall improvement, whereas in Poland the corresponding figure was almost $80 \%$.

Finally, although the greater improvement in life expectancy in the former GDR has narrowed the gap between the two parts of Germany, there are still important differences. Figure 4 shows the components of the life expectancy gap in 1997. Bars extending below the horizontal axis indicate that death rates in the age group concerned advantage the eastern part while bars above the axis indicate an advantage to the west.

For men, deaths at all ages were higher in East Germany but in particular among those aged over 15, resulting in an overall life expectancy gap of 2.1 years. While the differential among children and young adults was largely attributable to external causes, diseases of the digestive system became increasingly important from age 30 as did circulatory diseases from age 40 and neoplasms from age 50. Among those over 70 the differential was almost exclusively attributable to circulatory diseases.

The overall life expectancy gap of approximately one year in women was largely attributable to higher death rates among those over 60, mainly circulatory diseases. Those under 60 contributed only slightly to the differential, with infants actually doing somewhat better in the east. However, as in men, higher mortality among those aged 15-29 was

Table 2 Age standardised death rates for selected causes of death in the two parts of Germany and Poland: 1991/92 and 1996/97*

\begin{tabular}{|c|c|c|c|c|c|c|c|c|c|c|c|c|}
\hline & \multicolumn{4}{|c|}{ East Germany } & \multicolumn{4}{|c|}{ West Germany } & \multicolumn{4}{|l|}{ Poland } \\
\hline & \multicolumn{2}{|l|}{ Males } & \multicolumn{2}{|l|}{ Females } & \multicolumn{2}{|l|}{ Males } & \multicolumn{2}{|l|}{ Females } & \multicolumn{2}{|l|}{ Males } & \multicolumn{2}{|l|}{ Females } \\
\hline & 1992 & 1997 & 1992 & 1997 & 1992 & 1997 & 1992 & 1997 & 1991 & 1996 & 1991 & 1996 \\
\hline All causes & 1505.23 & 1276.96 & 911.15 & 747.78 & 1213.26 & 1110.62 & 736.02 & 682.38 & 1809.34 & 1620.90 & 1033.68 & 957.54 \\
\hline Infectious diseases & 5.14 & 4.00 & 2.47 & 2.57 & 12.86 & 11.72 & 6.00 & 7.09 & 15.17 & 11.41 & 5.11 & 4.18 \\
\hline Neoplasms & 322.13 & 309.31 & 188.54 & 173.14 & 324.54 & 298.84 & 191.44 & 178.13 & 351.66 & 363.53 & 182.78 & 187.84 \\
\hline respiratory cancer & 90.15 & 85.46 & 11.93 & 14.15 & 86.48 & 79.13 & 15.56 & 17.50 & 131.27 & 133.14 & 18.74 & 20.59 \\
\hline breast cancer & - & - & 29.72 & 26.05 & - & - & 35.48 & 34.34 & - & - & 24.00 & 25.97 \\
\hline prostate/cervix cancer & 30.61 & 33.40 & 14.77 & 11.21 & 39.33 & 36.52 & 9.64 & 8.43 & 21.93 & 26.00 & 18.30 & 17.32 \\
\hline Circulatory diseases & 761.43 & 623.77 & 510.75 & 408.61 & 552.30 & 492.65 & 361.07 & 325.81 & 1043.06 & 896.86 & 667.42 & 603.44 \\
\hline ischaemic heart disease & 370.62 & 338.92 & 207.77 & 191.68 & 255.43 & 230.06 & 127.51 & 120.61 & 236.99 & 198.08 & 84.42 & 78.36 \\
\hline cerebrovascular disease & 183.66 & 142.38 & 148.28 & 112.64 & 115.63 & 97.24 & 93.32 & 77.08 & 112.29 & 119.85 & 88.02 & 98.73 \\
\hline Respiratory diseases & 103.03 & 77.89 & 37.31 & 27.01 & 91.05 & 83.29 & 34.20 & 35.20 & 93.08 & 81.65 & 32.58 & 33.41 \\
\hline $\begin{array}{l}\text { bronchitis, emphysema, } \\
\text { asthma }\end{array}$ & 62.52 & 46.55 & 15.73 & 11.91 & 41.99 & 25.85 & 93.32 & 77.08 & 58.99 & 44.22 & 14.28 & 10.49 \\
\hline Digestive diseases & 88.86 & 73.54 & 43.3 & 35.10 & 55.00 & 50.74 & 31.87 & 30.34 & 57.36 & 56.56 & 31.30 & 30.00 \\
\hline $\begin{array}{l}\text { chronic liver disease and } \\
\text { cirrhosis }\end{array}$ & 51.71 & 44.83 & 17.37 & 15.54 & 28.22 & 25.75 & 12.29 & 11.00 & 22.37 & 22.56 & 8.67 & 7.93 \\
\hline Other diseases & 94.82 & 84.88 & 69.20 & 60.82 & 83.05 & 87.79 & 62.23 & 62.74 & 92.90 & 79.35 & 68.97 & 58.64 \\
\hline External causes & 109.21 & 82.99 & 46.85 & 29.80 & 64.21 & 55.77 & 29.26 & 23.47 & 156.11 & 131.53 & 45.52 & 40.04 \\
\hline motor vehicle accidents & 33.89 & 24.01 & 10.18 & 7.60 & 16.52 & 14.06 & 5.87 & 4.63 & 49.08 & 36.59 & 11.45 & 9.06 \\
\hline accidental poisoning & 3.17 & 1.02 & 1.58 & 0.27 & 0.32 & 0.30 & 0.18 & 0.17 & 17.07 & 12.91 & 3.35 & 2.00 \\
\hline accidental falls & 19.73 & 14.09 & 16.23 & 8.83 & 12.56 & 10.35 & 10.34 & 7.45 & 22.68 & 20.94 & 15.72 & 16.14 \\
\hline suicide & 32.00 & 27.41 & 10.85 & 7.51 & 22.28 & 20.50 & 7.83 & 6.77 & 30.65 & 30.77 & 5.19 & 5.27 \\
\hline
\end{tabular}

${ }^{\star}$ Standardised to the European population, ${ }^{43}$ ages $0-85$ years. 
KEY POINTS

- In the 1990s, life expectancy increased steeply in the former GDR and Poland, thereby narrowing the pre-transition gap to western Europe.

- The improvements were mainly attributable to falling death rates among young and middle aged men and women over 65

- In 1997, there was still a life expectancy gap between the two parts of Germany.

- Higher mortality from external causes, digestive and circulatory diseases in East German men and women accounts largely for the persisting health gap.

largely attributable to external causes while among those aged 30-49 diseases of the digestive system predominated.

This is also seen in age standardised death rates for selected causes (table 2). Despite improvements in deaths from diseases of the digestive system, mainly liver cirrhosis, rates in East Germany continue to be about twice those in West Germany and Poland. In both parts of Germany, about two thirds of the postunification decline in all cause mortality was attributable to circulatory diseases. In Poland, the corresponding figure was about $80 \%$, although rates still exceed those in Germany. The relative improvement in East Germany was largely attributable to falling rates of stroke while, in Poland, ischaemic heart diseases seem to have been more important.

\section{Discussion}

This study provides further insights into the health effects of political transition and, particularly, German unification. As reported for Poland, ${ }^{1}$ health transformation after transition had two phases, an initial worsening in 1988-1991 especially among young and middle aged men and subsequent improvements, largely attributable to external causes and cardiovascular diseases. The improvements have been much steeper in East Germany than in Poland.

\section{DATA QUALITY}

Changes in mortality patterns such as these raise questions about quality and completeness of data, especially the short lived deterioration in life expectancy during transition, and the impact of selective migration. This has been discussed in detail elsewhere. ${ }^{35}{ }^{6}$ One potential concern is the change in the definition of a live birth in October 1990. Definitions of live and stillbirths in the GDR differed from the west, with the consequence that some births classified as live in the west would have been stillbirths in the east. This led to underestimation of infant mortality as defined by WHO. ${ }^{7} \mathrm{~A}$ study in Saxony found no increase in male infant mortality from 1989 to 1990 and so did not influence the male life expectancy decline. ${ }^{8}$ However, for female infant mortality the deterioration attributable to the different definition was estimated to be 0.02 years or $18 \%$.
Changes in the definition of a live birth thus may be regarded of minor importance in relation to the short lived decline in life expectancy in the former GDR. ${ }^{5}$

The comparison must also take account of possible variation in coding practices. These differed between the former GDR and the old $\mathrm{FRG}^{9}$ but the western practice was adopted with unification. One consequence is a sudden change in mortality from some causes. This was observed in East Germany between 1990 and 1991, in particular for circulatory diseases, with deaths from myocardial infarction and stroke rising by $56 \%$ and $34 \%$, respectively. ${ }^{10}$ This seems likely to reflect adjustment of coding habits rather than a change in mortality patterns, an interpretation supported by the observation that all cause mortality changed only slightly. ${ }^{4}$ Although coding practices only changed in October 1990, discontinuities were visible earlier when mortality attributable to "signs, symptoms and ill-defined conditions" (ICD 780-799) suddenly increased in East Germany in $1990 .{ }^{46}$ This causes some problems in interpreting the 1989-90 change in cause specific mortality patterns in the former GDR and was the reason we selected 1992 as baseline.

In Poland, coding practice seems not to have changed with transition. ${ }^{11}$ Cause of death certification, however, apparently suffers from problems similar to those in the former GDR. $^{312}{ }^{13}$ Although this could affect comparability, use of broad diagnostic groups will minimise any effect.

THE TRANSITION PERIOD

As in most former Soviet bloc countries, men aged 20-59 years have been affected most by transition, with rising death rates from external causes and circulatory diseases. ${ }^{14}$ In both the former GDR and Poland the transient rise in mortality from external causes among the young was largely attributable to road traffic accidents, reflecting the sudden availability of western cars combined with increases in drunken driving, erosion of safety controls, poor transport infrastructure, and a possible deterioration of rescue services. ${ }^{1415}$ The temporary worsening in mortality of children and adolescents in East Germany was not seen in Poland or other central European countries, possibly reflecting a more rapid increase in traffic density in the former GDR.

Some caution is required when interpreting the apparently high impact of deaths from diseases of the digestive system among East German men compared with Poland. Both countries experienced an increase in liver cirrhosis mortality, somewhat steeper in the former GDR, at $18 \%$ in men and $14 \%$ in women, compared with $14 \%$ and $5 \%$ in Poland (data not shown). This seems surprising given the huge increase in alcohol consumption recorded for Poland between 1988 and 1991. One possibility is that it may reflect changes in coding practice, which, in Poland remained largely unchanged. Although this cannot be excluded, the impact of changing practice may be considered small as coding routine was 
actually not changed before October 1990. It thus seems more probable that cirrhosis rates in Poland were either under-recorded or that the increase in alcohol consumption had a greater impact on external causes of deaths than on cirrhosis. Furthermore, as the relative increase in deaths from cirrhosis in East Germany in 1989-90 was higher in the age group 15-39 (45 and $50 \%$ ) than in those aged 40-64 years $(18 \%)$, where diagnostic uncertainty might be assumed to be greater, the deterioration is likely to be genuine. The potential for sudden societal changes to cause such an increase in cirrhosis deaths is well recognised. ${ }^{16}$

Both countries also recorded a temporary increase in cardiovascular mortality during transition, which, in the former GDR, was indirectly confirmed by data from the East German MONICA centres. ${ }^{17}$ Between $1985 / 89$ and $1991 / 93$, the combined measure of attack rates and lethal events for myocardial infarction and stroke increased by about $15 \%$ in men aged 25 to 44 years, with a $44 \%$ increase in lethal events. Although still inadequately understood, one explanation may be psychosocial stress as the proportion of men and women experiencing loneliness and adverse life events significantly increased. ${ }^{17}$ Furthermore, rising stress levels predominantly affected those age groups displaying significant increases in myocardial infarction incidence.

CHANGING MORTALITY PATTERNS IN THE 1990s

The transition related worsening of mortality patterns resolved relatively soon in the former GDR and Poland with men in both countries returning to $1988 / 89$ levels in 1993 . The improvements especially in the former GDR have been much larger than expected, exceeding even optimistic predictions. ${ }^{18}$ While not refuting the hypothesis that stress accounted for some rise in mortality at transition, the size of the subsequent improvements suggests that this is not the only factor involved as mortality has declined while unemployment and uncertainty have not.

It is now widely believed that post-transition improvements in the east were at least partly attributable to rapid change in diet because of greater availability of imported fruit and vegetable oils. ${ }^{12}$ A study of the steep ischaemic heart disease mortality decline in Poland identified, after discussing several possible reasons, changes in dietary pattern as most probable. ${ }^{11}$ Intake of animal fat decreased and consumption of fresh fruits and vegetables increased in East Germany after unification. ${ }^{19}$ Although macronutrient composition of the East German diet seems not to have changed significantly, ${ }^{20}$ the intake of vitamins and minerals has. ${ }^{21}$ These changes may have contributed to the recent decline in cardiovascular mortality, in particular as improvements were most pronounced in stroke, which is considered to be strongly associated with fruit and vegetable consumption. ${ }^{22}$

In addition, prevalence of hypertension, defined according to $\mathrm{WHO},{ }^{23}$ fell by almost $5 \%$ to $25 \%$ between the early 1980 s and early 1990 s in East German women aged 25-64 years. ${ }^{24}$
Other evidence suggests a slight decline in mean systolic blood pressure in East German women (25-64 years) between the 1970s and 1990s. ${ }^{25}$ Although these data must be interpreted with caution, it is reasonable to assume at least some impact on female cardiovascular mortality, declining since the mid-1980s. Furthermore, smoking prevalence was reported to have declined in both parts of Germany, at least in men, ${ }^{24}{ }^{26}$ which might also contribute to falling cardiovascular mortality.

Evidence from other industrialised countries suggests that medical care also may have contributed to the decline in cardiovascular mortality. ${ }^{27}$ This might be expected to be important for those over 65 in East Germany, more so than in Poland, and to contribute to the accelerated mortality improvements among the oldest-old in East Germany reported elsewhere. ${ }^{28}$ While the impact of health care in Poland may be small as the system is still catching up with the economic and social changes taking place, ${ }^{29}{ }^{30}$ rebuilding the health care sector in East Germany after unification may reasonably be assumed to have contributed to increasing life expectancy. It made available, for instance, modern pharmaceutical drugs, considered the major explanation for the substantial decline in deaths from testicular cancer in the east. ${ }^{31}$ Large improvements in neonatal mortality may also be considered to be at least partly attributable to improvements in the quality of perinatal care, ${ }^{32}$ as in the Czech Republic. ${ }^{33}$

Living standards, especially for the elderly in the former GDR improved considerably after unification, ${ }^{34}$ and may be expected to have positively affected health and thus contributed to the accelerated decline in death rates. ${ }^{28}$ This is supported by the observation that measures of self perceived health at age 65 in East Germany seem to have increased since unification, ${ }^{35}$ which would be consistent with findings from elsewhere, showing self perceived health as a predictor of mortality. ${ }^{36}$

Notwithstanding the considerable improvements in deaths from external causes in both East Germany and Poland, only recently have rates returned to the pre-transition levels in young adults. Enforcement of safety controls and improvements in transport infrastructure may have contributed to these decreases. The overall decline, however, does not necessarily indicate a simultaneous drop in injury frequency but might rather be attributable to improvements in emergency services and medical care as well as injuries being less serious. ${ }^{37}$ Still, as in other post-communist countries, ${ }^{38}$ overall levels continue to be higher than in the west.

Despite the progress achieved in the former GDR, the mortality differential between the two parts of Germany, particularly in men, remains wide. Mortality from alcohol related diseases seems to be one of the major causes. It was estimated that in 1995 about $16 \%$ of male excess mortality in the east was attributable to alcohol related diseases; for men and women aged less than 65 years the proportion was even higher, at $27 \% .^{39}$ Although total alcohol 
consumption seems to differ only slightly between the two parts of Germany, there is evidence of higher consumption of hazardous amounts in the east. ${ }^{39}{ }^{40}$ Differences persist for other risk factors, such as micronutrient intake, which, despite recent improvements, remains lower in the east ${ }^{41}$ and may partly explain the continuing east-west cardiovascular mortality differential. This finds indirect support from a study revealing an unfavourable micronutrient profile in Czech men with high cardiovascular mortality compared with a south German sample. ${ }^{42}$ Furthermore, prevalence of hypertension, estimated at about $30 \%$ in East German men, ${ }^{24}$ increased cholesterol levels, and obesity still seem to be higher in the east.

In conclusion, while some trends in mortality in Germany and Poland have been described elsewhere, this study relates these trends specifically to changes in life expectancy so that their relative contribution can be seen more clearly. It highlights the possible role factors such as diet, alcohol consumption and medical care might have played in shaping post-transition trends in mortality. These findings have important implications for policy. Although further research is needed to understand better the relation of such factors to recent mortality trends, this study provides indicators of where countries might be able to learn from the experience of others.

Funding: EN is supported by a European Commission TMR Fellowship, no FMBICT983062

Conflicts of interest: none.

1 Zatoñski WA, Boyle P. Health transformations in Poland after 1988. F Epidemiol Biostat 1996;4:183-97.

2 Bobak M, Skodova Z, Pisa Z, et al. Political changes and trends in cardiovascular risk factors in the Czech Republic, 1985-92. F Epidemiol Community Health 1997;51:272-7.

3 Nolte E, Shkolnikov V, McKee M. Changing mortality patterns in east and West Germany and Poland. I: Long term terns in east and West Germany and Poland. I: Long term trends $(1960$

4 Brückner G. Todesursachen 1990/91 im vereinten Deutschland. Wirtschaft und Statistik 1993;4:257-78.

5 Eberstadt E. Demographic shocks after communism: Eastern Germany, 1989-93. Population Development Review 1994;20:137-52.

6 Häussler B, Hempel E, Reschke P. Die Entwicklung von Lebenserwartung und Sterblichkeit in Ostdeutschland nach der Wende (1989-1992). Gesundheitswesen 1995;57: 365-72.

7 Casper W, Wiesner G, Bergmann KE, eds. Mortalität und Todesursachen in Deutschland RKI-Heft 10/1995. Berlin: Robert Koch-Institut, 1995.

8 Rossa K, Schott J. Berechnung von Sterbetafeln und Trends der Lebensdauermaße für die Sächsische Bevölkerung im Zeitraum 1980 bis 1994. Gesundheitswesen 1997,59:315-

Zeitraun
20 .
9

Heinemann L, Barth W, Löwel H. Zur Validität der Herz-Kreislauf-Mortalitäts-Statistik der ehemaligen DDR Z Gesundheitswissenschaften 1998;6:108-19.

10 Hoffmeister H, Wiesner G. Akuter Herzinfarktdramatischer Sterblichkeitsanstieg in den neuen Bundesländern? Bundesgesundheitsblatt 1993;36:130

11 Zatonski WA, McMichael AJ, Powles JW. Ecological study of reasons for the sharp decline in mortality from ischaemic heart disease in Poland since 1991. BMF 1998;316:104751.

12 Cooper R, Schatzkin A, Sempos C. Rising death rates among Polish men. Int f Health Services 1984;14:289-302.

13 Heinemann L, Löwel H, Dahlke D, et al. Validity of the official cardiovascular mortality statistics. Acta Cardiol 1994; 159:338-40.
14 UNICEF. Crisis in mortality, health and nutrition. Florence: UNICEF International Child Development Centre Regional Monitoring Report No 2, 1994.

15 Winston FK, Rineer C, Menon R, et al. The carnage wrought by major economic change: ecological study of raffic related mortality and the reunification of Germany. BMF 1999;318:1647-9.

16 Edwards G, Anderson P, Babor T, et al. Alcohol policy and the public good. Oxford: Oxford University Press, 1994.

17 Barth W, Claßen E, Heinemann L, et al. Entwicklung der Herz-Kreislauf-Morbidität und -Mortalität in Ostdeutschland nach der politisch-ökonomischen Wende. $Z$ Gesundheitswissenschaften 1998;6:120-36.

18 Eberstadt N. Health and the fate of communist states. Communist Economies and Economic Transformation 1993;5:499517.

19 Winkler G, Brasche S, Heinrich J. Trends in food intake in adults from the city of Erfurt before and after the German reunification. Ann Nutr Metab 1997;41:283-90.

20 Hermann-Kunz E, Thamm M. Dietary recommendations and prevailing food and nutrient intakes in Germany. $\operatorname{Br} \mathcal{F}$ Nutr 1999;81 (suppl 2):S61-9.

21 Thiel C, Heinemann L. Nutritional behaviour differences in Germany. Rev Environ Health 1996;11:35-40.

22 Ness AR, Powles JW. Fruit and vegetables, and cardiovascular disease: a review. Int F Epidemiol 1997;26:1-13.

23 WHO MONICA Project. WHO MONICA Project: Risk factors. Int f Epidemiol 1989;18 (suppl 1):S46-55.

24 Heinemann L, Garbe E, Claßen E, et al. Trends im kardiovaskulären Risikofaktorenprofil in Ostdeutschland. $D M W$ 1998;123:889-95.

25 Heinemann L, Barth W, Hoffmeister H. Trend of cardiovascular risk factors in the east German population 19681992. F Clin Epidemiol 1995;48:787-95.

26 Helmert U. Analyse nationaler Trends kardiovaskulärer Risikofaktoren für die Bundesrepublik Deutschland von 1984 bis 1991. Z Gesundheitswissenschaften 1999;7:149-58.

27 Capewell S, Morrison CE, McMurrey JJ. Contribution of modern cardiovascular treatment and risk factor changes to the decline in coronary heart disease mortality in Scotland between 1975 and 1994. Heart 1999,81:380-6.

28 Gjonça A, Brockmann H, Maier H. Old-age mortality in Germany prior to and after unification. MPIDR Working Paper Wany prior to and after unification. MPIDR Working Paper graphic Research, 1999.

29 Cockerham WC, ed. Health and social change in Russia and eastern Europe. London: Routledge, 1999.

30 European Observatory on Health Care Systems, ed. Health care systems in transition: Poland. Copenhagen: European Observatory on Health Care Systems, 1999

31 Becker N, Boyle P. Decline in mortality from testicular cancer in West Germany after reunification. Lancet 1997;350:744.

32 Nolte E, Brand A, Koupilova I, et al. Neonatal and postneonatal mortality in Germany since unification. $\mathcal{F}$ Epidemiol Community Health 2000;54:84-90.

33 Koupilová I, McKee M, Holcik J. Neonatal mortality in the Czech Republic during the transition. Health Policy 1998;46:43-52.

34 Schmidt B. Zur Situation alter Menschen in Ostdeutschland. Deutschland-Archiv 1998;31:65-82.

35 Brückner G. Health expectancy in Germany: What do we learn from the reunification process? Tokyo: Nihon University Population Research Institute, 1998.

36 Idler EL, Benyamini Y. Self-rated health and mortality: a review of twenty-seven community studies. F Health Soc Behav 1997;38:21-37.

37 Casper W. Nichtnatürliche Todesfälle und Verletzungen im Rahmen von Mortalität und Morbidität. Bundesgesundheitsblatt 1998;41:3-8.

38 ECOHOST, ed. Childhood injuries: a priority area for the transition countries of Central and Eastern Europe and the newly independent states. London: LSH\&TM, 1998.

39 Statistisches Bundesamt, ed. Gesundheitsbericht für Deutschland 1998. Stuttgart: Metzler-Poeschel, 1998

40 Bloomfield K. Die Sozialepidemiogie des Alkoholkonsums im vereinigten Deutschland: Ergebnisse des Nationalen Surveys “Ost-West 1991". Gesundheitswesen 1997;59:A44.

41 Winkler G, Brasche S, Döring A, et al. Dietary intake of middle-aged men from an East and a West German city after the German reunification: do differences still exist? Eur 7 Clin Nutr 1998;52:98-103.

42 Bobak M, Hense HW, Kark J, et al. An ecological analysis of determinants of coronary heart disease rates: a comparison of Czech, Bavarian and Israeli men. Int $\mathcal{f}$ Epidemiol 1999;25:437-44

43 Waterhouse JAH, Muir CS, Correa P, eds. Cancer incidence in five continents. Lyon: International Agency for Research on Cancer, 1976. 